\title{
ARBORIZAÇÃO EM PRAÇAS NO MUNICÍPIO DE JATAÍ, GO, BRASIL
}

Érica Virgínia Estêfane de Jesus Amaral ${ }^{1}$, Frederico Augusto Guimarães Guilherme ${ }^{2}$

\section{RESUMO}

Arborização urbana refere-se ao conjunto de árvores que compõem o paisagismo de uma cidade, plantadas em áreas verdes, como em parques e praças, destinadas ao incentivo da vida comunitária. A cidade de Jataí, localizada no Sudoeste do Estado de Goiás, destaca-se por seus lagos e parques, porém é notória a falta de planejamento em áreas públicas. Assim, o estudo teve o objetivo de analisar a arborização de praças da cidade, por meio de um estudo quali-quantitativo das espécies arbóreas. As 14 praças escolhidas foram as maiores e mais frequentadas pela população. Todas as árvores adultas foram contabilizadas, além das mudas de árvores recém-plantadas. Foram registrados 1030 indivíduos, pertencentes a 33 famílias botânicas e 81 espécies. As espécies mais frequentes foram Syagrus oleracea (Gueiroba) com 430 indivíduos encontrados em 12 praças e Poincianella pluviosa (Sibipiruna) com 146 indivíduos em 11 praças. Algumas praças apresentaram boa variedade de espécies, porém seis delas não apresentaram mais do que dez espécies. Aproximadamente $27 \%$ das árvores corresponderam a indivíduos imaturos e jovens, demonstrando uma recente preocupação do poder público com a arborização.

Palavras-chave: Áreas verdes; Espécies nativas; Qualidade de vida; Paisagismo urbano. 


\section{URBAN ARBORIZATION IN SQUARES OF THE JATAÍ CITH, GOIÁS, BRAZIL}

\section{ABSTRACT}

Urban tree refers to the set of woody plants that make up the landscape of a city, planted in green sites, such as parks and squares, for the encouragement of community life. The Jataí city, located in southwestern of Goiás State, has notoriety for its lakes and parks, but there is evident lack of planning in civil areas. So, this study aimed to examine the urban trees in squares, through a quali-quantitative study of tree species. The 14 largest squares and most frequented by the population were chosen, located in the center and peripheric sectors of the city. All the adult trees were accounted, besides the recently planted trees. Were registered 1030 individuals belonging to 33 botanical families and 81 species. The most frequent species were the palm Syagrus oleracea (Gueiroba) with 430 individuals found in 12 squares and Poincianella pluviosa (Sibipiruna) with 146 individuals found in 11 squares. Some squares showed a good variety of species, but six of them showed no more than ten species. About $27 \%$ of the trees corresponded to immature and young plants, demonstrating a recent worry of the government with afforestation.

Kewwords: Urban green sites; Human welfare; Native species; Urban landscaping.

\section{INTRODUÇÃO}

A preservação, recuperação e criação de espaços verdes urbanos têm sido uma das preocupações de estudiosos e planejadores urbanos, já que apresentam importância para a qualidade ambiental e de vida da população (SILVEI RA; BARROS, 2001). A arborização visa melhorias nas condições microclimáticas, diminuição da poluição e ornamentação, preocupando-se com a harmonia entre os plantios e as obras de infra-estrutura urbana, como pavimentação de ruas e passeios, saneamento, eletrificação e telecomunicação (MILANO, 1986).

Arborização urbana refere-se a todas as plantas de porte arbóreo que compõem a vegetação de uma cidade, portanto, árvores plantadas em passeios e calçadas fazem parte da arborização, porém não são consideradas como integrantes de áreas verdes (LOBODA; 
DE ANGELIS, 2005). A arborização pode ser considerada como fator determinante da salubridade ambiental, influenciando diretamente o bem-estar do homem, em virtude dos múltiplos benefícios que proporciona ao meio, como o embelezamento pelo variado colorido que exibe (DANTAS; SOUZA, 2004).

Áreas verdes são tratadas como espaços urbanos livres, onde predominam árvores e outras formas de vida vegetais. São espaços abertos, acessíveis e relacionados com recreação, proporcionando interação das atividades humanas com o meio ambiente, correspondendo, em geral, ao que se conhece como parques, jardins ou praças (HARDER et al., 2006).

Praças em específico são definidas como áreas verdes destinadas ao incentivo à vida comunitária, servindo como ponto de encontro da população, proporcionando melhoria na qualidade de vida já que se destinam ao lazer, paisagismo e preservação ambiental (HARDER et al., 2006). Dentre as áreas verdes urbanas, as praças tendem a oferecer fácil acesso e interação entre a população e meio ambiente, permitindo atividades recreacionais e de descanso.

Pereira (2008) cita que a praça é uma criação física do homem e é por excelência palco da vida pública na cidade, tendo sobrevivido às transformações ao longo dos séculos. Esse mesmo autor ainda afirma que a praça tem significado imprescindível na vida da cidade e de sua população, sendo um espaço desafogado e livre de construções, onde o terreno é permeável e a estrutura verde pode ser entendida como um oásis na matriz urbana. Porém, Silva Filho (2003) contradiz essa afirmação relatando que, com o tempo, as mudanças vieram e as praças foram deixando de ser um espaço prioritário de recreação. Atualmente, a maioria das pessoas tem outras necessidades e sentem o mundo a seu redor de modo diferente. Isso não significa que as praças precisam ficar no esquecimento, pois são ecologicamente importantes, possuem valores estéticos, e auxiliam na redução da amplitude térmica e novos usos podem ser estendidos a elas.

A seleção de espécies para áreas verdes urbanas deve levar em consideração fatores como o porte, o tipo de raízes e a resistência dos ramos. As praças são lugares praticamente livres de calçamento e fiação, podendo optar-se pelo plantio de árvores com porte maior, mas sempre atentando para espécies com ramos mais resistentes ou com frutos de menor tamanho e peso. Sem esses cuidados, acidentes indesejáveis com a população humana, eventualmente podem ser causados pelas árvores.

Diferentes espécies de árvores se adéquam aos diferentes lugares e algumas proporcionam maior insatisfação à população do que outras (ALVES; GOUVEIA, 1995). Por isso é necessário um estudo prévio para selecionar as árvores para os diferentes locais de 
plantio. Para Santana e Santos (1999), na escolha da espécie para arborizar, o gosto pessoal deve ser sempre colocado em segundo plano, em relação às necessidades da coletividade. Características botânicas da espécie vegetal, arquitetônicas e paisagísticas do local a ser arborizado, devem nortear a escolha.

O uso de espécies nativas na arborização urbana vem ganhando espaço e trazendo importantes ganhos ambientais, estéticos e, principalmente, culturais para as cidades (MACHADO et al., 2006). A substituição contínua da flora nativa por plantas exóticas altera o ambiente natural que resta nos centros urbanos, além de uniformizar as paisagens de diferentes cidades, contribuindo para a redução da biodiversidade no meio urbano, dissociando-o do contexto ambiental onde se insere.

O Código Municipal de Meio Ambiente do município de Jataí, define praça como logradouro público, limitado por via de circulação de veículos, destinados ao lazer, recreação, e a permitir a infiltração de águas pluviais, para realimentação do lençol freático.

O município de Jataí, estado de Goiás, está localizado a 327 km da capital Goiânia. Possui uma população estimada de 86 mil habitantes (IBGE, 2010), sendo considerada a capital dos grãos do estado e conhecida pelo seu potencial turístico e pelos lagos e parques artificiais. O Cerrado é o bioma predominante na região, sendo típico da zona tropical, caracterizado por uma vegetação de fisionomia e flora próprias (PINTO, 1993), classificado dentro dos padrões de vegetação do mundo como savana, destaca-se pela alta biodiversidade e ocorrência de espécies endêmicas, sendo considerada a mais rica savana do mundo (KLINK; MACHADO, 2005).

Dentre tantas benfeitorias no município de Jataí, há uma notória incipiência na arborização das praças urbanas. Um estudo realizado sobre a arborização presente nas ruas da cidade registrou a presença de inúmeras espécies exóticas ou plantadas inadequadamente, que podem trazer prejuízos em calçadas, conflitos como redes aéreas de distribuição de energia e em canais pluviais da cidade (BARROS et al., 2010).

Nesse contexto, esse estudo teve o objetivo de realizar um levantamento qualiquantitativo com a identificação e caracterização das espécies arbóreas plantadas em 14 praças do município de Jataí, GO.

\section{MATERIAIS E MÉTODOS}

O levantamento quali-quantitativo da arborização urbana foi feito entre os meses de janeiro e julho de 2010, em praças da cidade de Jataí, macrorregião sudoeste do estado de 
Goiás ( $\left.17^{\circ} 53^{\prime} \mathrm{S} ; 5^{\circ} 43^{\prime} \mathrm{W}\right)$. Das 14 praças elencadas para o estudo, foram selecionadas aquelas mais conhecidas e frequentadas, incluindo centro da cidade e alguns bairros. As praças foram separadas em dois grupos: praças do centro (06) e praças dos bairros (08), seguindo definições do município, apesar de alguns bairros serem confundidos com o setor central da cidade.

As praças do centro da cidade foram: Praça Dom Germano Vega Compon, Praça da Igreja Matriz, Praça Tenente Diomar Menezes, Praça Professor Maromba, Praça Olho d'água e Praça da Igreja São Sebastião. As praças dos bairros foram: Praça Coriolando Leles Barroso, Praça Dom Miguel Pedro Mundo, Praça da Igreja São Judas Tadeu, Praça da Bíblia, Praça da Catedral Divino Espírito Santo, Praça da Bandeira, Praça Clodoaldo Rezende, Praça José Nunes de Oliveira. A figura 1 mostra a distribuição dessas praças no perímetro urbano da cidade de Jataí.

Fez se o levantamento de todos os indivíduos arbóreos, ou seja, com fuste único, retilíneo e lenhoso, inclusive das plantas jovens de espécies arbóreas. Palmeiras com estipe exposto tem o hábito arborescente e, portanto, foram consideradas no estudo. Para a avaliação da distribuição de tamanho e tempo de plantio, foram adotadas três categorias de classes de altura: mudas de árvores recém plantadas $(<2 \mathrm{~m})$, árvores jovens com tempo de plantio intermediário e que ainda não atingiram a maturidade reprodutiva, (2-5 $\mathrm{m}$ ) árvores adultas, com tempo de plantio avançado e produzindo flores e frutos $(>5 \mathrm{~m})$. As árvores registradas nas 14 praças foram contabilizadas, adotando o método de inventário do tipo censo, com a identificação de todas as espécies arbóreas encontradas.

Alguns indivíduos que não puderam ser identificados em campo tiveram partes dos ramos coletados, herborizados e depositados no acervo do Herbário Jataiense $(\mathrm{HJ})$, da Universidade Federal de Goiás. Registros fotográficos foram feitos, especialmente daquelas espécies não identificadas, visando auxiliar na identificação botânica. Portanto, muitas espécies arbóreas, já conhecidas por sua ampla utilização na arborização de cidades, tiveram sua identificação feita diretamente no campo, ou ainda com auxílio de literatura específica e de taxonomistas. Algumas espécies não tiveram sua identificação confirmada, visto que não foram encontradas em flor e/ou fruto durante o período de coleta. Para a classificação taxonômica das espécies foi adotado o sistema de classificação APG III (2009), e os nomes científicos e respectivas autorias foram conferidos na Lista de espécies da flora do Brasil (http://floradobrasil.jbrj.gov.br) além de apoio do banco eletrônico do Jardim Botânico de Missouri (Tropicos.org. Missouri Botanical Garden) para espécies exóticas.

Batista et al. (2013) sugere o uso do termo "nativa regional" para diferenciar espécies 
que são nativas da região fitogeográfica do Brasil onde está sendo realizado o trabalho e, nativas, para espécies nativas no Brasil, mas que pertencem a outras regiões fitogeográficas para não atribuir características ecológicas às espécies que não pertencem a determinada região. Com isso, as espécies foram agrupadas em três categorias: nativas do Cerrado, região fitogeográfica local; nativas do Brasil, encontradas em outras regiões fitogeográficas do Brasil, exceto o Cerrado; e exóticas, para aquelas não encontradas naturalmente no Brasil. Os dados foram processados e analisados em planilha eletrônica Excel, visando análise da riqueza de espécies, e a proporção entre exóticas e nativas.

Figura 1. Distribuição das 14 praças estudadas, no perímetro urbano de Jataí, GO, Brasil Figure 1. Distribution of 14 squares studied, in the perimeter of the Jataí city, GO, Brazil

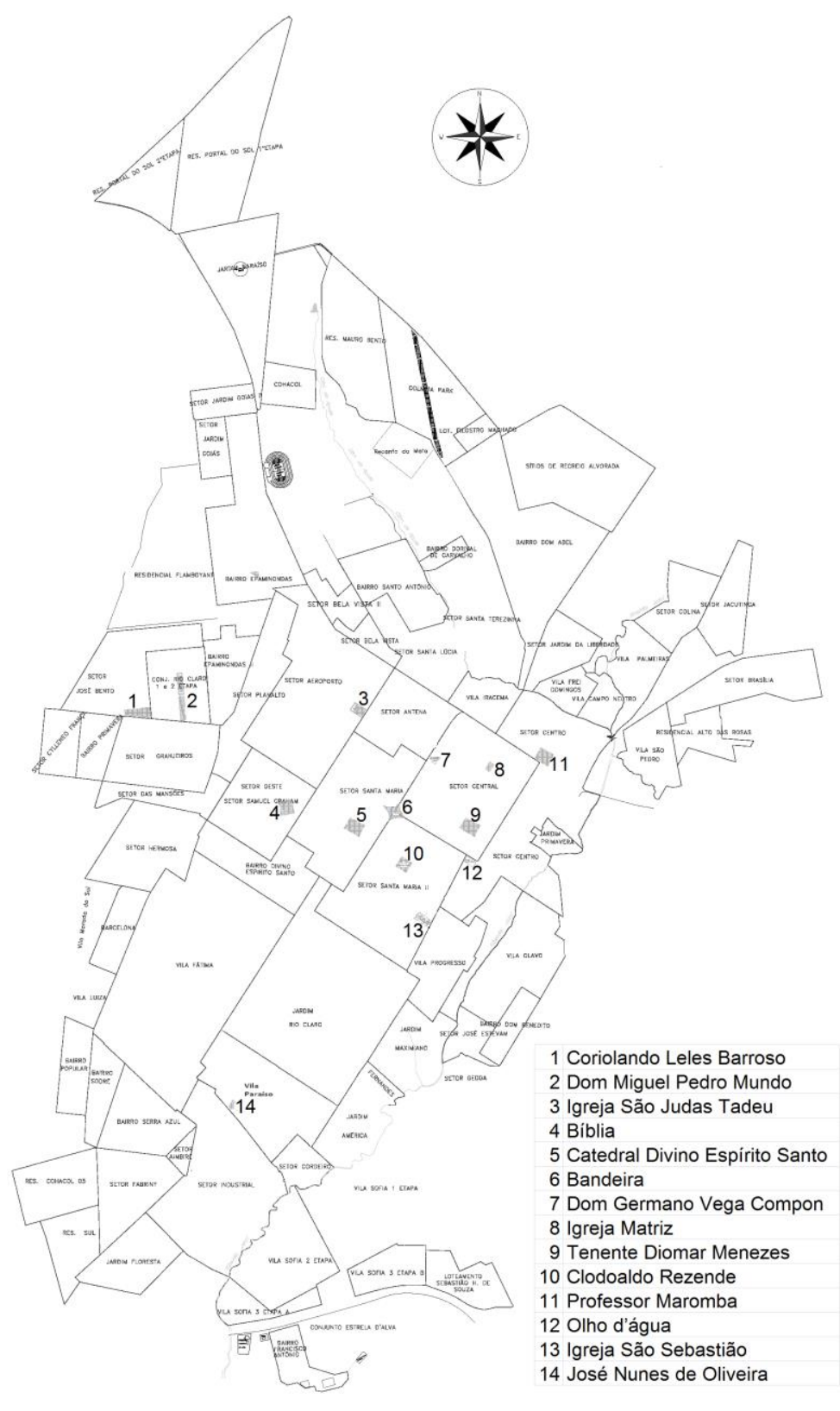




\section{RESULTADOS E DISCUSSÃO}

Foi registrado um total de 1030 árvores, distribuídas em 33 famílias e 81 espécies ao longo das 14 praças estudadas (Tabela 1). A família Fabaceae apresentou a maior riqueza florística, com 15 espécies, dentre as quais três foram exóticas e 12 nativas do Brasil, sendo que destas, sete são nativas do Cerrado. Poincianella pluviosa (Sibipiruna) foi bem representativa no estudo, com 146 indivíduos distribuídos em 11 praças. Esta é uma espécie muito utilizada na arborização urbana pela sua copa exuberante e caducifolia parcial, o que faz com que proporcione sombra o ano todo. Em estudo feito no Campus da Universidade de Brasília, esta espécie também figurou entre as mais abundantes (KURIHARA et al., 2005).

A família Arecaceae também teve destaque nesse estudo, apresentando o segundo lugar em número de espécies, embora tenha mostrado a maior abundância de exemplares. Esse maior número de indivíduos ocorreu em função principalmente da espécie Syagrus oleracea (Gueiroba ou Palmito-amargo), planta nativa do Cerrado e bastante apreciada pela culinária goiana. Esta foi a espécie mais abundante do levantamento, sendo registrados 430 indivíduos (41,7\% do total) distribuídos em 12 praças. Esse fato pode ser explicado pelo potencial ornamental que esta planta apresenta, por ter rápido desenvolvimento e, por ser de fácil produção e/ou aquisição de mudas, já que se encontra em seu habitat natural. Por outro lado, a espécie não proporciona boa sombra e caracteriza a falta de opções ou até mesmo criatividade na escolha de espécies.

Nota-se que mais da metade de todos os indivíduos encontrados na arborização das praças (57\%) pertencem a essas duas espécies. Como citado por Dantas e Souza (2004) não é recomendável a predominância de uma ou poucas espécies na arborização urbana, sendo conveniente manter uma variabilidade dos espécimes sempre seguindo a estética e observando-se o lado paisagístico. Melo et al. (2007) relatam que a predominância de apenas uma espécie ou grupo de espécies pode facilitar a propagação de pragas, atualmente muito comum nas árvores em ambientes urbanos.

Barros et al. (2010) em levantamento da arborização em diferentes quadras de Jataí, embora tenham registrado tanto Poincianella pluviosa (Sibipiruna) como Syagrus oleracea (Gueiroba) ao longo das ruas da cidade, constataram que as espécies mais abundantes ao longo das calçadas foram Licania tomentosa (Oiti) e Ficus benjamina (Ficus). Segundo esses autores, Licania tomentosa (Oiti) apresenta inúmeras características benéficas e apropriadas ao uso na arborização urbana. Sendo assim, poucas espécies totalizam a maioria dos indivíduos encontrados na arborização, tanto em praças como em calçadas na cidade de Jataí. Outros autores como Bortoleto et al. (2007), Pires et al. (2007), Rocha et al. 
(2004) e Silva Filho et al. (2002) também registraram poucas espécies representando a maioria dos indivíduos encontrados na arborização urbana de Águas de São Pedro-SP, Goiandira-GO, Nova Iguaçu-RJ e Uberlândia-MG, respectivamente. Oiti, Sibipiruna e Ficus estão sempre presentes, indicando que são espécies comumente encontradas na arborização urbana de várias cidades no Brasil.

Tabela 1. Relação das espécies encontradas na arborização das praças na cidade de Jataí, GO, com seus respectivos nomes populares e famílias botânicas, origem, número de praças em que cada espécie ocorre e o número total de indivíduos

Table 1. List of species found in the arborization of the squares in the Jataí city, GO, with their vernacular names and botanical families, origin, number of squares in which each species occurs and the total number of individuals

\begin{tabular}{|c|c|c|c|c|c|}
\hline Família & Espécie & $\begin{array}{l}\text { Nome } \\
\text { Popular }\end{array}$ & Origem & $\begin{array}{l}\text { N.. - de } \\
\text { Praças }\end{array}$ & $\begin{array}{l}\mathrm{N} .{ }^{\circ} \text { total } \\
\text { indivíduos }\end{array}$ \\
\hline Anacardiaceae & $\begin{array}{l}\text { Anacardium occidentale } \\
\mathrm{L} \text {. }\end{array}$ & Cajueiro & $\begin{array}{l}\text { Nativa do } \\
\text { Cerrado }\end{array}$ & 1 & 1 \\
\hline Anacardiaceae & $\begin{array}{l}\text { Astronium cf graveolens } \\
\text { Jacq. }\end{array}$ & Guaritá & $\begin{array}{l}\text { Nativa do } \\
\text { Cerrado }\end{array}$ & 1 & 2 \\
\hline Anacardiaceae & Mangifera indica $\mathrm{L}$. & Mangueira & Exótica & 3 & 8 \\
\hline Anacardiaceae & Schinus molle L. & - & Exótica & 1 & 2 \\
\hline Annonaceae & Annona mucosa Jacq. & Graviola & $\begin{array}{l}\text { Nativa do } \\
\text { Brasil }\end{array}$ & 1 & 1 \\
\hline Apocynaceae & Nerium oleander L. & Espirradeira & Exótica & 2 & 3 \\
\hline Apocynaceae & Plumeria rubra L. & $\begin{array}{l}\text { Jasmim- } \\
\text { manga }\end{array}$ & Exótica & 1 & 8 \\
\hline Araliaceae & $\begin{array}{l}\text { Schefflera actinophylla } \\
\text { (Endl.) Harms }\end{array}$ & $\begin{array}{l}\text { Cheflera } \\
\text { gigante }\end{array}$ & Exótica & 3 & 18 \\
\hline Araliaceae & $\begin{array}{l}\text { Schefflera arboricola } \\
\text { Hayata }\end{array}$ & $\begin{array}{l}\text { Cheflera } \\
\text { pequena }\end{array}$ & Exótica & 1 & 1 \\
\hline Araucariceae & $\begin{array}{l}\text { Araucaria angustifolia } \\
\text { (Bertol.) Kuntze }\end{array}$ & $\begin{array}{l}\text { Pinheiro-do- } \\
\text { paraná }\end{array}$ & $\begin{array}{l}\text { Nativa do } \\
\text { Brasil }\end{array}$ & 1 & 2 \\
\hline Araucariceae & $\begin{array}{l}\text { Araucaria columnaris } \\
\text { (JR Forst.) Hook. }\end{array}$ & $\begin{array}{l}\text { Pinheiro-de- } \\
\text { Natal }\end{array}$ & Exótica & 2 & 2 \\
\hline Arecaceae & $\begin{array}{l}\text { Acrocomia aculeata } \\
\text { (Jacq.) Lodd. ex Mart. }\end{array}$ & Macaúba & $\begin{array}{l}\text { Nativa do } \\
\text { Cerrado }\end{array}$ & 2 & 3 \\
\hline Arecaceae & $\begin{array}{l}\text { Attalea phalerata Mart. } \\
\text { ex Spreng. }\end{array}$ & Bacuri & $\begin{array}{l}\text { Nativa do } \\
\text { Cerrado }\end{array}$ & 2 & 19 \\
\hline Arecaceae & Caryota mitis Lour. & $\begin{array}{l}\text { Rabo-de- } \\
\text { peixe }\end{array}$ & Exótica & 1 & 1 \\
\hline Arecaceae & Caryota urens $\mathrm{L}$. & $\begin{array}{l}\text { Rabo-de- } \\
\text { peixe }\end{array}$ & Exótica & 3 & 18 \\
\hline Arecaceae & $\begin{array}{l}\text { Dypsis decaryi (Jum.) } \\
\text { Beentje \& J. Dransf. }\end{array}$ & $\begin{array}{l}\text { Palmeira- } \\
\text { triângulo }\end{array}$ & Exótica & 4 & 18 \\
\hline Arecaceae & Livistona sp & Palmeira & Exótica & 1 & 1 \\
\hline Arecaceae & Mauritia flexuosa L. f. & Buriti & $\begin{array}{l}\text { Nativa do } \\
\text { Cerrado }\end{array}$ & 1 & 1 \\
\hline
\end{tabular}




\begin{tabular}{|c|c|c|c|c|c|}
\hline Arecaceae & $\begin{array}{l}\text { Phoenix roebelenii } \\
\text { O'Brien }\end{array}$ & Fênix & Exótica & 3 & 18 \\
\hline Arecaceae & $\begin{array}{l}\text { Roystonea regia (Kunth) } \\
\text { O.F.Cook }\end{array}$ & Palmeira-real & Exótica & 6 & 21 \\
\hline Arecaceae & $\begin{array}{l}\text { Syagrus oleracea (Mart.) } \\
\text { Becc. }\end{array}$ & $\begin{array}{l}\text { Gueiroba, } \\
\text { guariroba }\end{array}$ & $\begin{array}{l}\text { Nativa do } \\
\text { Cerrado }\end{array}$ & 12 & 430 \\
\hline Arecaceae & $\begin{array}{l}\text { Syagrus romanzoffiana } \\
\text { (Cham.) Glassman }\end{array}$ & Gerivá & $\begin{array}{l}\text { Nativa do } \\
\text { Cerrado }\end{array}$ & 2 & 4 \\
\hline Bignoniaceae & $\begin{array}{l}\text { Handroanthus cf } \\
\text { impetiginosus (Mart. ex } \\
\text { DC.) Mattos }\end{array}$ & Ipê-roxo & $\begin{array}{l}\text { Nativa do } \\
\text { Cerrado }\end{array}$ & 4 & 9 \\
\hline Bignoniaceae & $\begin{array}{l}\text { Handroanthus } \\
\text { chrysotrichus (Mart. ex } \\
\text { A. DC.) Mattos }\end{array}$ & Ipê-amarelo & $\begin{array}{l}\text { Nativa do } \\
\text { Cerrado }\end{array}$ & 2 & 10 \\
\hline Bignoniaceae & $\begin{array}{l}\text { Jacaranda cuspidifolia } \\
\text { Mart. ex A. DC. }\end{array}$ & Caroba & $\begin{array}{l}\text { Nativa do } \\
\text { Cerrado }\end{array}$ & 2 & 8 \\
\hline Bignoniaceae & $\begin{array}{l}\text { Tabebuia cf heterophylla } \\
\text { (DC.) Britt. }\end{array}$ & Ipê-rosa & $\begin{array}{l}\text { Nativa do } \\
\text { Cerrado }\end{array}$ & 7 & 26 \\
\hline Bignoniaceae & $\begin{array}{l}\text { Tabebuia roseoalba } \\
\text { (Ridl.) Sandwith }\end{array}$ & Ipê-branco & $\begin{array}{l}\text { Nativa do } \\
\text { Cerrado }\end{array}$ & 3 & 8 \\
\hline Bixaceae & Bixa orellana L. & Urucum & $\begin{array}{l}\text { Nativa do } \\
\text { Brasil }\end{array}$ & 1 & 2 \\
\hline Caryocaraceae & $\begin{array}{l}\text { Caryocar brasiliense } \\
\text { Cambess. }\end{array}$ & Pequi & $\begin{array}{l}\text { Nativa do } \\
\text { Cerrado }\end{array}$ & 1 & 1 \\
\hline Cecropiaceae & $\begin{array}{l}\text { Cecropia pachystachya } \\
\text { Trécul }\end{array}$ & Embauba & $\begin{array}{l}\text { Nativa do } \\
\text { Cerrado }\end{array}$ & 1 & 1 \\
\hline Chysobalanaceae & $\begin{array}{l}\text { Licania tomentosa } \\
\text { (Benth.) Fritsch }\end{array}$ & Oiti & $\begin{array}{l}\text { Nativa do } \\
\text { Brasil }\end{array}$ & 6 & 48 \\
\hline Cupressaceae & $\begin{array}{l}\text { Platycladus cf orientalis } \\
\text { (L.) Franco }\end{array}$ & Tuia & Exótica & 1 & 1 \\
\hline Cycadaceae & Cycas circinalis $\mathrm{L}$. & Cica & Exótica & 3 & 7 \\
\hline Dilleniaceae & Dillenia indica L. & Vilena & Exótica & 2 & 2 \\
\hline Euphorbiaceae & Croton urucurana Baill. & $\begin{array}{l}\text { Sangra- } \\
\text { d'água }\end{array}$ & $\begin{array}{l}\text { Nativa do } \\
\text { Cerrado }\end{array}$ & 1 & 1 \\
\hline Fabaceae & $\begin{array}{l}\text { Anadenanthera } \\
\text { peregrina var. falcata } \\
\text { (Benth.) Altschul }\end{array}$ & Angico & 0 & 1 & 2 \\
\hline Fabaceae & Bauhinia blakeana Dunn & Pata-de-vaca & $\begin{array}{l}\text { Nativa do } \\
\text { Cerrado }\end{array}$ & 1 & 2 \\
\hline Fabaceae & Cassia fistula $\mathrm{L}$. & $\begin{array}{l}\text { Chuva-de- } \\
\text { ouro }\end{array}$ & Exótica & 4 & 4 \\
\hline Fabaceae & $\begin{array}{l}\text { Delonix regia (Bojer ex } \\
\text { Hook.) Raf. }\end{array}$ & Flamboyant & $\begin{array}{l}\text { Nativa do } \\
\text { Cerrado }\end{array}$ & 7 & 8 \\
\hline Fabaceae & $\begin{array}{l}\text { Erythrina humeana } \\
\text { Spreng. }\end{array}$ & Mulungu & $\begin{array}{l}\text { Nativa do } \\
\text { Cerrado }\end{array}$ & 1 & 1 \\
\hline Fabaceae & Erythrina variegata $\mathrm{L}$. & Brasileirinha & $\begin{array}{l}\text { Nativa do } \\
\text { Cerrado }\end{array}$ & 1 & 1 \\
\hline Fabaceae & Fabaceae sp1 & - & $\begin{array}{l}\text { Nativa do } \\
\text { Brasil }\end{array}$ & 1 & 2 \\
\hline Fabaceae & $\begin{array}{l}\text { Hymenaea cf martiana } \\
\text { Hayne }\end{array}$ & Jatobá & $\begin{array}{l}\text { Nativa do } \\
\text { Brasil }\end{array}$ & 1 & 2 \\
\hline Fabaceae & Hymenaea courbaril L. & Jatobá & $\begin{array}{l}\text { Nativa do } \\
\text { Brasil }\end{array}$ & 4 & 5 \\
\hline
\end{tabular}




\begin{tabular}{|c|c|c|c|c|c|}
\hline Fabaceae & $\begin{array}{l}\text { Hymenaea stigonocarpa } \\
\text { Mart. ex Hayne }\end{array}$ & Jatobá & Exótica & 1 & 1 \\
\hline Fabaceae & $\begin{array}{l}\text { Inga cf laurina (Sw.) } \\
\text { Willd. }\end{array}$ & Ingá & $\begin{array}{l}\text { Nativa do } \\
\text { Cerrado }\end{array}$ & 1 & 1 \\
\hline Fabaceae & Inga sp & Ingá & $\begin{array}{l}\text { Nativa do } \\
\text { Cerrado }\end{array}$ & 1 & 1 \\
\hline Fabaceae & $\begin{array}{l}\text { Leucaena leucocephala } \\
\text { (Lam.) de Wit }\end{array}$ & Leucena & $\begin{array}{l}\text { Nativa do } \\
\text { Cerrado }\end{array}$ & 1 & 3 \\
\hline Fabaceae & $\begin{array}{l}\text { Libidibia ferrea (Mart. ex } \\
\text { Tul.) L.P.Queiroz }\end{array}$ & Pau-ferro & $\begin{array}{l}\text { Nativa do } \\
\text { Brasil }\end{array}$ & 1 & 1 \\
\hline Fabaceae & $\begin{array}{l}\text { Poincianella pluviosa } \\
\text { (DC.) L.P.Queiroz }\end{array}$ & Sibipiruna & $\begin{array}{l}\text { Nativa do } \\
\text { Brasil }\end{array}$ & 11 & 158 \\
\hline Fabaceae & $\begin{array}{l}\text { Schizolobium parahyba } \\
\text { (Vell.) S.F. Blake }\end{array}$ & Guapuruvu & Exótica & 1 & 1 \\
\hline Indeterminada & Indeterminada 1 & - & 0 & 1 & 1 \\
\hline Indeterminada & Indeterminada 2 & - & 0 & 1 & 1 \\
\hline Indeterminada & Indeterminada 3 & - & 0 & 1 & 1 \\
\hline Lauraceae & Persea americana Mill. & Abacateiro & Exótica & 1 & 1 \\
\hline Liliaceae & $\begin{array}{l}\text { Beaucarnea recurvata } \\
\text { Lem. }\end{array}$ & Biucarnea & $\begin{array}{l}\text { Nativa do } \\
\text { Cerrado }\end{array}$ & 1 & 6 \\
\hline Lythraceae & Lagerstroemia indica L. & Resedá & Exótica & 4 & 17 \\
\hline Malpighiaceae & $\begin{array}{l}\text { Lophanthera lactescens } \\
\text { Ducke }\end{array}$ & $\begin{array}{l}\text { Chuva-de- } \\
\text { ouro }\end{array}$ & $\begin{array}{l}\text { Nativa do } \\
\text { Brasil }\end{array}$ & 3 & 3 \\
\hline Malvaceae & $\begin{array}{l}\text { Ceiba speciosa (A. St.- } \\
\text { Hil.) Ravenna }\end{array}$ & $\begin{array}{l}\text { Paineira, } \\
\text { Barribuda }\end{array}$ & $\begin{array}{l}\text { Nativa do } \\
\text { Cerrado }\end{array}$ & 3 & 4 \\
\hline Malvaceae & Hibiscus rosa-sinensis L. & Hibisco & $\begin{array}{l}\text { Nativa do } \\
\text { Brasil }\end{array}$ & 1 & 1 \\
\hline Malvaceae & Pachira aquatica Aubl. & Monguba & $\begin{array}{l}\text { Nativa do } \\
\text { Brasil }\end{array}$ & 2 & 2 \\
\hline Melastomataceae & $\begin{array}{l}\text { Tibouchina cf } \\
\text { stenocarpa (Schrank \& } \\
\text { Mart. ex DC.) Cogn. }\end{array}$ & Quaresmeira & $\begin{array}{l}\text { Nativa do } \\
\text { Cerrado }\end{array}$ & 2 & 2 \\
\hline Meliaceae & Cedrela fissilis Vell. & Cedro rosa & $\begin{array}{l}\text { Nativa do } \\
\text { Brasil }\end{array}$ & 1 & 3 \\
\hline Moraceae & $\begin{array}{l}\text { Artocarpus heterophyllus } \\
\text { Lam. }\end{array}$ & Jaqueira & Exótica & 1 & 1 \\
\hline Moraceae & $\begin{array}{l}\text { Brosimum gaudichaudii } \\
\text { Trécul }\end{array}$ & Mama-cadela & $\begin{array}{l}\text { Nativa do } \\
\text { Cerrado }\end{array}$ & 1 & 1 \\
\hline Moraceae & Ficus benjamina L. & Ficus & $\begin{array}{l}\text { Nativa do } \\
\text { Brasil }\end{array}$ & 6 & 29 \\
\hline Moraceae & $\begin{array}{l}\text { Ficus cf catappifolia } \\
\text { Kunth \& Bouché }\end{array}$ & Gameleira & Exótica & 1 & 3 \\
\hline Moraceae & Ficus lyrata Warb. & Figueira & Exótica & 2 & 12 \\
\hline Moraceae & Ficus sp & Figueira & Exótica & 1 & 2 \\
\hline Moringaceae & Moringa oleifera Lam. & Moringa & Exótica & 1 & 1 \\
\hline Muntigiaceae & Muntingia calabura L. & Calabura & Exótica & 2 & 4 \\
\hline Musaceae & $\begin{array}{l}\text { Ravenala } \\
\text { madagascariensis Soon. }\end{array}$ & $\begin{array}{l}\text { Árvore-do- } \\
\text { viajante }\end{array}$ & $\begin{array}{l}\text { Nativa do } \\
\text { Brasil }\end{array}$ & 1 & 1 \\
\hline Myrtaceae & $\begin{array}{l}\text { Callistemon viminalis } \\
\text { (Sol. ex Gaertn.) G. Don }\end{array}$ & $\begin{array}{l}\text { Escova-de- } \\
\text { garrafa }\end{array}$ & Exótica & 1 & 2 \\
\hline
\end{tabular}




\begin{tabular}{lllllc} 
Myrtaceae & $\begin{array}{l}\text { Plinia cauliflora (Mart.) } \\
\text { Kausel }\end{array}$ & Jaboticaba & $\begin{array}{l}\text { Nativa do } \\
\text { Brasil }\end{array}$ & 2 & 2 \\
\hline Myrtaceae & Psidium guajava L. & Goiabeira & $\begin{array}{l}\text { Nativa do } \\
\text { Brasil }\end{array}$ & 3 & 5 \\
\hline Pandanaceae & $\begin{array}{l}\text { Pandanus cf tectorius } \\
\text { Parkinson ex Du Roi }\end{array}$ & Pandano & $\begin{array}{l}\text { Nativa do } \\
\text { Brasil }\end{array}$ & 1 & 1 \\
\hline Polygonaceae & Triplaris americana L. & Triplaris & Exótica & 1 & 10 \\
\hline Rubiaceae & Genipa americana L. & Jenipapo & $\begin{array}{l}\text { Nativa do } \\
\text { Brasil }\end{array}$ & 1 & 3 \\
\hline Rutaceae & Citrus limon (L.) Burm. f. & Limão & $\begin{array}{l}\text { Nativa do } \\
\text { Cerrado }\end{array}$ & 1 & 4 \\
\hline Rutaceae & Murraya paniculata (L.) & Murta & Exótica & 3 & 7 \\
\hline Sapindaceae & Sapindaceae sp1 & - & Exótica & 1 & 1 \\
\hline Total & & & & 1030 \\
\hline
\end{tabular}

As praças onde se observou uma arborização com maior número de plantas e com maior variedade de espécies estão localizadas na região central, como as Praças da Igreja Matriz e Olho D'Água. Isso demonstra uma maior preocupação com a estética destes locais quando comparados com praças mais periféricas, onde o número de indivíduos e a riqueza de espécies foram marcadamente menores. Consequentemente a área sombreada destas praças é relativamente menor, gerando maior desconforto térmico e diminuindo a socialização que estes locais têm como objetivo de proporcionar a população.

Uma praça da periferia e que deve ser destacada positivamente quanto ao número de espécies utilizadas na arborização é a Praça Dom Miguel Pedro Mundo (Tabela 2), localizada no Conjunto Rio Claro I, que é um dos mais antigos bairros da cidade. Segundo informações da placa fixada neste local, foi inaugurado no ano de 1989, criado como Companhia de Habitação de Goiás (Cohab).

Praças como Professor Maromba são bem arborizadas, porém a maior parte das árvores se encontram distantes dos bancos que se destinam ao descanso da população. Isso é prejudicial em relação à socialização, já que praças são pontos de encontro, cujo principal intuito é incentivar a vida comunitária (HARDER et al., 2006).

A Praça Coriolando Leles Barroso, localizada no Setor José Bento, na periferia da cidade, apesar de se destacar com o maior número de árvores, é uma das praças com o menor número de espécies (Tabela 2), já que possui uma predominância de indivíduos de Syagrus oleraceae (Gueiroba), o que foge dos padrões de recomendação, como já discutido, devido ao pouco sombreamento que proporciona. 
Tabela 2. Lista das praças estudadas, total de indivíduos (NI), total de espécies (Nspp) encontradas e área total das praças na cidade de Jataí, GO

Table 2. List of the studied squares, total of individuals (NI), total of species (Nspp) found and total area of the squares in the Jataí city, GO

\begin{tabular}{lrrr}
\hline Praça & NI & Nspp & Área $\left.\mathbf{( m}^{\mathbf{2}}\right)$ \\
\hline Dom Miguel Pedro Mundo (P) & 125 & 37 & 13845 \\
\hline Bandeira (P) & 102 & 22 & 4050 \\
\hline Tenente Diomar Menezes (C) & 68 & 18 & 9405 \\
\hline Bíblia (P) & 77 & 16 & 10816 \\
\hline Igreja Matriz (C) & 104 & 15 & 6996 \\
\hline Clodoaldo Rezende (P) & 83 & 14 & 7031 \\
\hline Olho d'água (C) & 133 & 13 & 3773 \\
\hline Catedral Divino Espírito Santo (P) & 50 & 11 & 21700 \\
\hline Igreja São Judas Tadeu (P) & 49 & 10 & 1840 \\
\hline Professor Maromba (C) & 51 & 6 & 10976 \\
\hline Igreja São Sebastião (C) & 9 & 4 & 899 \\
\hline Coriolando Leles Barroso (P) & 143 & 4 & 11773 \\
\hline José Nunes de Oiveira (P) & 17 & 4 & 1083 \\
\hline Dom Germano Veja Compon (C) & 19 & 3 & 1044 \\
\hline
\end{tabular}

As espécies nativas do Cerrado contemplaram 53\% das espécies registradas, enquanto 23\%, 20\% e 4\% das espécies foram nativas do Brasil, exóticas e não identificadas quanto à origem, respectivamente (Tabela 3). Esses resultados contrastam com o estudo de Barros et al. (2010), que registraram predomínio de espécies exóticas arborizando as ruas da cidade de Jataí. O maior número de espécies nativas encontradas no atual estudo se deu pela grande quantidade de indivíduos de Syagrus oleraceae (Gueiroba), nativa do Cerrado e Poincianella pluviosa (Sibipiruna), nativa do Brasil, registrado nas praças estudadas.

Tabela 3. Relação da origem das espécies, número de espécies por origem e total de indivíduos arbóreos encontrados para cada tipo de distribuição geográfica

Table 3. Relation of the origin of species, number of species per origin and total of the trees found for each type of geographic distribution

\begin{tabular}{llr}
\hline Origem & Espécies & Total \\
\hline Não identificadas & 10 & 12 \\
\hline Exótica & 28 & 213 \\
\hline Nativa do Brasil & 18 & 253 \\
\hline Nativa do Cerrado & 25 & 552 \\
\hline Total & $\mathbf{8 1}$ & $\mathbf{1 0 3 0}$ \\
\hline
\end{tabular}


Observa-se que aproximadamente $14 \%$ dos indivíduos arbóreos corresponderam a mudas de árvores, $13 \%$ a árvores jovens e $74 \%$ a árvores adultas (Tabela 4). Grande parte desse padrão se deve à recente preocupação do poder público com a arborização, pois se pode-se observar que em oito praças ocorre predomínio de árvores recém plantadas. Este é o caso da Praça da Bíblia, onde se verifica que $80,5 \%$ das árvores encontradas são mudas e juvenis, portanto, plantadas recentemente. Resultado semelhante foi observado por Resende e Santos (2010) em uma avaliação quali-quantitativa da arborização das praças do bairro Jaraguá, em Uberlândia, MG, onde destaca-se a existência de árvores recém plantadas, devido a um processo de arborização iniciado pela prefeitura nos últimos anos.

Tabela 4. Distribuição por classes de altura das árvores encontradas nas praças do centro e da periferia da cidade de Jataí, GO

Table 4. Distribution of the trees size classes found in squares in the center and the outskirts of Jataí city, GO

\begin{tabular}{lccc}
\hline Classes de Alturas & Centro & Periferia & Total \\
\hline Mudas de árvores $(<2 \mathrm{~m})$ & 333 & 413 & 746 \\
\hline Árvores jovens $(2-5 \mathrm{~m})$ & 18 & 117 & 135 \\
\hline Árvores adultas $(>5 \mathrm{~m})$ & 33 & 116 & 149 \\
\hline Total & $\mathbf{3 8 4}$ & $\mathbf{6 4 6}$ & $\mathbf{1 0 3 0}$ \\
\hline
\end{tabular}

\section{CONCLUSÕES}

O estudo registrou um total de 1030 indivíduos distribuídos em 81 espécies e 33 famílias botânicas nas 14 praças avaliadas na cidade de Jataí. As espécies mais abundantes e com grande potencial na arborização urbana da região foram Syagrus oleraceae (Gueiroba) e Poincianella pluviosa (Sibipiruna).

Em torno de $80 \%$ das árvores registradas são espécies nativas das formações vegetais brasileiras, e $27 \%$ dos indivíduos arbóreos corresponderam a mudas e árvores jovens. Portanto, conclui-se que existe o hábito de se utilizar espécies arbóreas ocorrentes naturalmente na região, e também demonstra uma preocupação recente do poder público com o uso das espécies não exóticas na arborização urbana. 


\section{REFERÊNCIAS}

ALVES, S.M.; GOUVEIA, V.V. Atitudes em relação a arborização urbana: Uma contribuição da psicologia ambiental para a qualidade de vida urbana. Textos do laboratório de Psicologia Ambiental, Brasília, DF, v. 4, n. 6, p. 1-6, 1995.

ANGIOSPERM PHYLOGENY GROUP (APG) III. An update of the angiosperm phylogeny group classification for the orders and families of flowering plants: APG III. Botanical Journal of the Linnean Society, London, v. 161, n. 2, p. 1-17, 2009.

BARROS, E.F.S.; GUILHERME, F.A.G.; CARVALHO, R. S. Arborização urbana em quadras de diferentes padrões construtivos na cidade de Jataí. Revista Árvore, Viçosa, MG, v. 34, n. 2, p. 287-295, 2010.

BATISTA, M.L.; LOPES, A.G.; CARVALHO, F.A.; SILVA, L.F.; GALVES, N.; PEDRO, N.F.; STRANGHETTI, V. Indicação de essências regionais do nordeste paulista para enriquecimento da arborização de ruas, praças e avenidas. Revista da Sociedade Brasileira de Arborização Urbana, Piracicaba, SP, v. 8, n. 1, p. 75-88, 2013.

BORTOLETO, S.; SILVA FILHO, D.F.; SOUZA, V.C.; FERREIRA, M.A.P.; POLIZEL, J.L.; RIBEIRO, R.C.S. Composição e distribuição da arborização viária da estância de Águas de São Pedro-SP. Revista da Sociedade Brasileira de Arborização Urbana, Piracicaba, SP, v. 2, n. 3, p. 32-46, 2007.

DANTAS, C.I.; SOUZA, C.M.C. Arborização urbana na cidade de Campina Grande - PB: Inventário e suas espécies. Revista de Biologia e Ciências da Terra, Campina Grande, PB, v. 4, n. 2, 2004.

HARDER, I.C.F.; RIBEIRO, R.C.S.; TAVARES, A.R. Índice de área verde e cobertura vegetal para as praças do município de Vinhedo, SP. Revista Árvore, Viçosa, MG, v. 30, n. 2, p. 277-282, 2006.

IBGE. Instituto Brasileiro de Geografia e Estatística. Censo 2010. Disponível em: http://www.ibge.gov.br/home/estatistica/populacao/censo2010/GO2010.pdf Acesso em 24 nov. 2010.

JATAÍ. Código Municipal de Meio Ambiente. Disponível em: < http://www.jatai.go.gov.br/ index.php?option=com_docman\&ltemid=172>. Acesso em: 03 Ago. 2009.

KLINK, C.A.; MACHADO, R.B. A conservação do Cerrado Brasileiro. Megadiversidade. Brasília. v. 1. n. 1, p. 147-155, 2005. 
KURIHARA, D.L.; IMAÑA-ENCINAS, J.; PAULA, J.E. Levantamento da arborização do Campus da Universidade de Brasília. Cerne, Lavras, MG, v. 11, n. 2, p. 127-136, 2005.

LISTA DE ESPÉCIES DA FLORA DO BRASIL. Jardim Botânico do Rio de Janeiro. Disponível em: <http://floradobrasil.jbrj.gov.br/>. Acesso em: 07 Mai. 2015.

LOBODA, C.R.; DE ANGELIS, B.L.D. Áreas verdes públicas urbanas: Conceitos, usos e funções. Ambiência, Guarapuava, PR, v. 1, n. 1, p. 125-139, 2005.

MACHADO, R.R.B.; MEUNIER, I.M.J.; SILVA, J.A.A; CASTRO, A.A.J.F. Árvores nativas para a arborização de Teresina, Piauí. Revista da Sociedade Brasileira de Arborização Urbana, Piracicaba, SP, v. 1, n. 1, p. 10-18, 2006.

MELO, R.R.; LIRA FILHO, J.A.; JÚNIOR, F.R. Diagnóstico qualitativo e quantitativo da arborização urbana no bairro Bivar Olinto, Patos, Paraíba. Revista da Sociedade Brasileira de Arborização Urbana, Piracicaba, SP, v. 2, n. 1, p. 64-80, 2007.

MILANO, M.S. O planejamento da arborização, as necessidades de manejo e tratamentos culturais das árvores de ruas de Curitiba-PR. Revista Floresta, Curitiba, PR, v. 17, n. 12, p. 15-21, 1986.

PEREIRA, M.M.D.C. Praças Púbicas Sustentáveis - caso de renovação das praças. Lisboa, Portugal, 2008.

PINTO, M.N. Cerrado: Caracterização, ocupação e perspectivas. 2 ed. Brasília: Editora UnB, 1993.

PIRES, N.A.M.T. MELO, M.S.; OLIVEIRA, D.E.; XAVIER-SANTOS, S. Diagnóstico da arborização do município de Goiandira, Goiás. Revista Brasileira de Biociências, Porto Alegre, RS, v. 5, n. 1, p. 537-539, 2007.

REZENDE, T.M.; SANTOS, D.G. Avaliação quali-quantitativa da arborização das praças do bairro Jaraguá, Uberlândia - MG. Revista da Sociedade Brasileira de Arborização Urbana, Piracicaba, SP, v. 5, n. 2, p. 139-157, 2010.

ROCHA, R.T.; LELES, P.S.S.; NETO, S.N.O. Arborização de vias públicas em Nova Iguaçu, RJ: O caso dos bairros Rancho Novo e Centro. Revista Árvore, Viçosa, MG, v. 28, n. 4, p. 599-607, 2004.

SANTANA, J.R.F.; SANTOS, G.M.M. Arborização do Campus da UEFS: Exemplo a ser seguido ou um grande equívoco? Sitientibus, Feira de Santana, BA, n. 20, p. 103-107, 1999. 
SILVA FILHO, D.F.; PIZETTA, P.U.C.; ALMEIDA, J.B.S.A.; PIVETTA, K.F.L.; FERRAUDO, A.S. Banco de dados relacional para cadastro, avaliação e manejo da arborização em vias públicas. Revista Árvore, Viçosa, MG, v. 26, n. 5, p. 629-642, 2002.

SILVA FILHO, D.F. Silvicultura Urbana - O desenho florestal da cidade. Departamento de Ciências Florestais da ESALQ/USP, São Paulo, p. 1-16, 2003.

SILVEIRA, G.; BARROS, M.V.F. Perfil geoambiental das praças: região norte da cidade de Londrina-PR. Semina: Ci. Exatas Tecnol, Londrina, PR, v. 22, p. 63-71, 2001.

TROPICOS.ORG. Missouri Botanical Garden. Disponível em: <http://www.tropicos.org>. Acesso em: 02 jul. 2014. 